\title{
Personality and Education Mining based Job Advisory System
}

\author{
Rajendra S. Choudhary ${ }^{1}$, Rajul Kukreja ${ }^{1}$, Nitika Jain ${ }^{1}$, Shikha Jain ${ }^{1}$ \\ ${ }^{1}$ Jaypee Institute of Information Technology, Noida, India.
}

\begin{abstract}
Every job demands an employee with some specific qualities in addition to the basic educational qualification. For example, an introvert person cannot be a good leader despite of a very good academic qualification. Thinking and logical ability is required for a person to be a successful software engineer. So, the aim of this paper is to present a novel approach for advising an ideal job to the job seeker while considering his personality trait and educational qualification both. Very well-known theories of personality like MBTI indicator and OCEAN theory, are used for personality mining. For education mining, score based system is used. The score based system captures the information from attributes like most scoring subject, dream job etc. After personality mining, the resultant values are coalesced with the information extracted from education mining. And finally, the most suited jobs, in terms of personality and educational qualification are recommended to the job seekers. The experiment is conducted on the students who have earned an engineering degree in the field of computer science, information technology and electronics. Nevertheless, the same architecture can easily be extended to other educational degrees also. To the best of the author's knowledge, this is a first e-job advisory system that recommends the job best suited as per one's personality using MBTI and OCEAN theory both.
\end{abstract}

Keywords - E-job advisory system, Education mining, job recommendation system, Personality mining.

\section{INTRODUCTION}

$I^{\prime}$ $\mathrm{N}$ today's world of internet so-called e-world, searching a dream job is very tedious. Lots of information, job proposals and job search engines are available. If we try to search one job, we will get a huge list of recommendation, but still finding out the most ideal and suitable one, that we will truly enjoy in the future, is very difficult.

The online job portals like naukri.com, indeed.com etc. provides two-way search options: one from the recruiter side where recruiter can filter the candidates who are matched with their expectations in terms of educational qualification. And the second is for the job seekers who upload their CV and look for the jobs best fit to their qualification. However, a recent research conducted by Cave [7] has shown that although, there is a range of skill sets involved in any tech career, the personality also puts a significant impact on the output generated at the workplace and the society, in general. For any job, the employer looks for candidate with some specific abilities. The discipline you studied is only one of the factors in the consideration. Every job demands an employee with some special qualities. For example, numbers of options are available for an (IT) engineering students like in our field of software development, testing, marketing, academics, research etc. The minimum educational qualification for all these jobs is an engineering degree in the field of computer science or information technology. As per survey conducted to see the recent trend, more than $42 \%$ of the students want to go for MBA after completing engineering degree, $40 \%$ want to become software developer and remaining wants to opt for testing, academics or others. This is what we call as dream career. But how much successful they become on getting their dream career? This is a big question. Research [2], [3], [4], [6], [7], [8], [10] conducted in this field has shown that the performance at the workplace highly depends upon your personality along with your knowledge. According to John Perry, a Senior Server Engineer and IT Architect at City of Mesa, Arizona [7], "Being an INTJ in an IT leadership position has been beneficial; this is due to the fact that we are pre-wired to create efficient organizations and systems just by our very nature."

Unfortunately, the personality traits which is an important attribute to decide job success, is missing in all widely used job recommending tools. To address this missing attribute, we present a novel approach for finding a relationship between the personality traits, education qualification and job for a candidate. The objective is to recommend the ideal jobs to a job seeker while conducting personality mining and education mining both. This will help in increasing the level of job satisfaction among employees and a better performance at the workplace. For personality mining, the job seeker has to fill a questionnaire. The design of this questionnaire is based upon Myers-Briggs Type Indicator (MBTI) [1]. On the basis of the response of the candidate, MBTI score is obtained. Then, these results are mapped on to the five personality dimensions (Openness, Conscientiousness, Extroversion, Agreeableness, and Neuroticism) as suggested by OCEAN theory [9]. Why not OCEAN theory directly? In the model, MBTI is used to evaluate the personality of job seeker because the MBTI based questionnaire is available in renowned literatures. MBTI to 
OCEAN mapping is done because as compared to MBTI, the dimensions proposed by OCEAN theory are closer to the personality traits required for suggesting jobs and are used by human resource team of any organization to describe the personality of an employee. Finally, the extracted personality is combined with the score of educational qualification of the candidate to suggest him best suited job rank-wise. In this paper, we have conducted the experimentation on students who have an earned engineering degree in the field of computer science, information technology and electronics. However, the same architecture can easily be extended to other educational degrees also.

To the best of the author's knowledge, this is a first e-job advisory system that recommends the job best suited as per one's personality and knowledge both.

The rest of this work is organized as follows. Section II discusses the personality theories used. Literature work is given in section III. Next our proposed model is described in section IV, followed by the implementations and results in section $\mathrm{V}$ and finally concluding the paper with future scope in section VI.

\section{BACKGROUND}

Personality mining refers to predicting the personality of a person based upon some feedback, questionnaire or using some social networking sites like Facebook, LinkedIn etc. In our proposed system, two personality theories are used: MBTI and OCEAN theory.

\section{A. The Myers-Briggs Type Indicator (MBTI)}

MBTI [1] assessment is a set of psychometric questionnaire designed to measure psychological preferences that is how people perceive the world and make decisions. In MBTI, personality traits are calculated in 8 different factors.

Extraversion (E)-(I) Introversion: Extrovert and Introvert refer to where people focus their attention to get their energy either the OUTER or INNER world. Extroverts act first and think/reflect later whereas introverts think/reflect first and act later.

Sensing (S)-(N) Intuition: Sensing and intuition are the information-gathering (perceiving) functions. They describe how new information is understood and interpreted. Sensing people mentally live in the Present, attending to present opportunities. Intuitive people mentally live in the Future, attending to future possibilities.

Thinking $\quad(T)-(F) \quad$ Feeling: Thinking and feeling are the decision-making (judging) functions. Thinking people instinctively search for facts and logic in a decision situation. Feeling people instinctively employ personal feelings and impact on people in decision situations.

Judgment $(J)-(P)$ Perception: People also have a preference for using either the judging function (thinking or feeling) or their perceiving function (sensing or intuition) when relating to the outside world (extraversion). Judging people plan many of the details in advance before moving into action. Perceiving people are comfortable moving into action without a plan; plan on-the-go.

\section{B. OCEAN Theory}

OCEAN [9] is also known as Big Five personality theory. It suggests five broad domains or dimensions of personality that are used to describe human personality. Openness: It refers to the number of interests to which on is attracted and the depth to which those interests are pursued. High openness refers to a person with relatively more interests and, consequently, relatively less depth within each interest, while low openness refers to a person with relatively few interests and relatively more depth in each of those interests.

Conscientiousness: It refers to goal-directed behavior. High conscientiousness refers to a person who focuses intensely on his/her goals and exhibits the self-discipline associated with such focus. Low conscientiousness refers to one who is disorganized and distracted.

Extraversion: It refers to the number of relationships with which one is comfortable. High extraversion is characterized by a larger number of relationships and a larger proportion of one's time spent in enjoying them. Low extraversion is characterized by a smaller number of relationships and a smaller proportion of one's time spent in pursuing those relationships.

Agreeableness: It refers to one's general interpersonal orientation. High agreeableness describes a person who reacts to others with warmth and will bend to avoid conflict. Low agreeableness describes one who, in the extreme, only follows one's inner voice regardless of hurting others.

Neuroticism: Contrasts emotional stability and eventemperedness with negative emotionality, such as feeling anxious, nervous, sad, and tense. Emotional Stability refers to one's proneness to negative emotions and anxiety.

MBTI is a standard scale and a fixed MBTI questionnaire to measure the personality trait. So, in this paper we have first extract the personality from the feedback form of the job seeker on MBTI scale and then it is mapped over the OCEAN theory to interpret MBTI findings within a broader, more commonly shared conceptual framework.

\section{RELATED WORK}

For the last few decades, many researchers are working in the field of job recommendation system for job seekers and erecruitment system for employers to make the system more intelligent and smart. In 2007, Meo [8] has proposed XML based multi-agent recommender system for online recruitment services. They have used XML as standard mechanism for user information representation. They also evaluated their work performance by doing comparisons from previous known results. But their system does not include job seekers personality rather they are recommending on the basis of seekers educational qualification only. Lounsbury [6] related personality traits and career satisfaction of human resource professionals, defining that optimism, emotional resilience, 
assertiveness and extraversion are powerful traits of managers or human resource professionals. Those with low levels of these traits were recommended to be coached to develop optimism-enhancing, to learn defensive pessimism strategies or engage in counseling or stress management programs. Nagarjuna [12] conducted a study for comparing engineers with commerce students, shows that engineering students are more self-reliant, realistic, responsible and emotionally tough. Engineering students are more socially aware, controlled, selfdisciplined and perfectionists as compared to the commerce background students. Faliagka [3] proposed an online recruitment system using personality factors and ranked job seekers according to Analytic Hierarchy Process (AHP). Faliagka [2] proposed another recruitment system where they evaluated the performance of job seekers by extracting data from LinkedIn and blogs. But the system was not efficient as a very few people write blogs and this should not be used as personality mining criteria. Secondly, the proposed model is for recruiter only not for the job seekers. Moreover, in 2014, Cave [7] wrote an article on how he used MBTI theory in his organization. With the help of various examples, he explained the role of MBTI personality types in IT careers.

The conclusion is that there is a relationship between personality trait and ideal job for a job seeker to have better output at workplace. Some of the researchers have recognized the importance of personality and proposed the personality based e-recruitment system. However, no one has worked for job advisory system for job seekers.

\section{OUR MODEL: E-PE JOB}

E-PE Job is a Job Advisory System based upon personality and education mining. The system suggests automated ranked jobs based on a set of criteria which can help the job seeker to search for a most appropriate job. In the current system, our main focus is on two criteria for job selection: personality mining and educational qualification. The system architecture is shown in figure 1 . The whole system is arranged in three phases as explained below:
1) In the first phase, a set of questions are given from MBTI questionnaire to the job seeker to get information for personality analysis. The educational skills are extracted through online form or $\mathrm{CV}$ filled by the candidate. Applicant fills an online form with his most scoring subject and the subject of his interest. Candidate's desired job profiles are also asked.

2) In the second phase, data analysis is done from data gathered in phase 1. Firstly, the response to these questions is analyzed to extract the personality traits of the candidate. These questions extract different factors of personality traits of MBTI theory. After that MBTI score is mapped over five personality dimensions (Openness, Conscientiousness, Extroversion, Agreeableness, and Neuroticism) as suggested by OCEAN theory. This is done because OCEAN five factors are the collection of characteristics found in nearly all personality and psychological tests and it gives more specific and more detailed personality traits of any candidate. The coefficient values for mapping MBTI to OCEAN (Big Five Personality traits) have been taken from [11]. The conversion process is as follows:

Let

$\mathrm{MB}_{\mathrm{i}}$ : MBTI score vector for 8 personality traits

$\mathrm{M}_{\mathrm{i}}$ : vector that stores difference in values of (E-I), $(\mathrm{S}-\mathrm{N}),(\mathrm{T}-\mathrm{F})$, and $(\mathrm{J}-\mathrm{P})$

$\mathrm{MO}_{\mathrm{ij}}$ : 2-D matrix store the MBTI to OCEAN mapping coefficients( as shown in table 1).

$\mathrm{C}_{\mathrm{ij}}$ : intermediate result

$\mathrm{O}_{\mathrm{j}}$ : OCEAN score vector

Then

$$
\begin{aligned}
& \mathrm{M}_{\mathrm{i}}=\mathrm{MB}_{2 * \mathrm{i}-1}-\mathrm{MB}_{2 * \mathrm{i}} \\
& \mathrm{C}_{\mathrm{ij}}=\mathrm{M}_{\mathrm{i}} * \mathrm{MO}_{\mathrm{ij}} \\
& \mathrm{O}_{\mathrm{j}}=\Sigma_{\mathrm{i}->1 \text { to } 4 \mathrm{C}_{\mathrm{ij}}}
\end{aligned}
$$

Finally the value of different factors of OCEAN is obtained in the vector $\mathrm{O}_{\mathrm{j}}$.

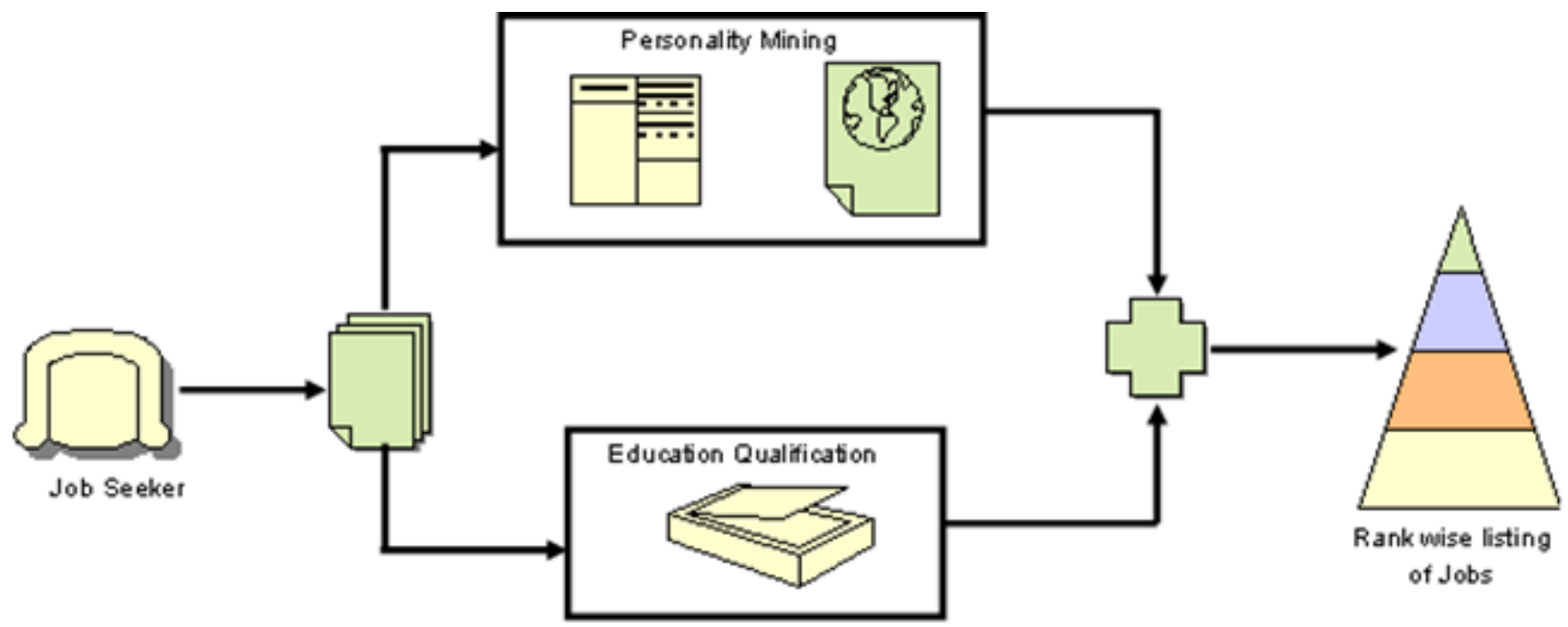

Fig 1: E-PE Job : Proposed system architecture 
TABLE I

CORRELATION FACTORS FOR MAPPING MBTI OVER OCEAN

\begin{tabular}{|l|l|l|l|l|l|}
\hline & $\begin{array}{l}\text { Extra- } \\
\text { version }\end{array}$ & $\begin{array}{l}\text { Openn- } \\
\text { ess }\end{array}$ & $\begin{array}{l}\text { Agree- } \\
\text { ableness }\end{array}$ & $\begin{array}{l}\text { Conscien } \\
\text { tiousness }\end{array}$ & $\begin{array}{l}\text { Neuro- } \\
\text { ticism }\end{array}$ \\
\hline E-I & -0.74 & 0.03 & -0.03 & 0.08 & 0.16 \\
\hline S-N & 0.10 & 0.72 & 0.04 & -0.15 & -0.06 \\
\hline T-F & 0.19 & 0.02 & 0.44 & -0.15 & 0.06 \\
\hline J-P & 0.15 & 0.30 & -0.06 & -0.49 & 0.11 \\
\hline
\end{tabular}

Moreover, based upon the education choices filled as shown in figure 2, different weight factors are assigned. For example, a weight factor of 40,45 or 50 is assigned based on educational analysis. All desired jobs are given some priority and hence are given a weight of 40 . Moreover, if most scored subject is same as subject of his interest, weight 50 is given otherwise they are given weight of 45 each. Finally, all the scores are summed up to get the aggregated score of educational qualification (E).

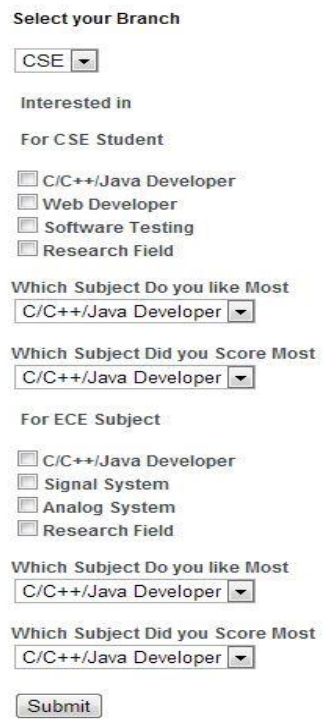

Fig 2: Snap shot of Questionnaire

3) In the third phase, coalescence is to be done by combining both educational analysis and personality traits analysis. Reference [5] has given the relationship between various parameters of the OCEAN theory with engineering degree based job profiles. In the proposed model, we have used this relationship as $\mathrm{Wij}$.

To find the weight factor corresponding to each job profile $\left(\mathrm{JO}_{\mathrm{i}}\right)$,

$$
\mathrm{JO}_{\mathrm{i}}=\Sigma_{\mathrm{i}>1} \text { to } 5\left(\left(\mathrm{O}_{\mathrm{j}}+\mathrm{E}\right) / \mathrm{W}_{\mathrm{ij}}\right)
$$

Finally, two weight factors, one calculated by the educational qualification and second by the personality mining are combined together (using equation 4) to get the compatibility index of the applicant with the corresponding job.
TABLE II

OCEAN SCORE MAPPING WITH ENGINEERING DEGREE BASED JOB PROFILES

\begin{tabular}{|l|l|l|l|l|l|}
\hline & O & C & E & A & N \\
\hline Web Developer & 67.65 & 54.07 & 47.87 & 54.76 & 62.34 \\
\hline Software Developer & 54.32 & 53.67 & 56.45 & 46.78 & 52.75 \\
\hline R \& D & 63.59 & 58.65 & 67.84 & 61.67 & 58.63 \\
\hline Data Analyst & 45.56 & 47.66 & 51.53 & 56.45 & 46.85 \\
\hline Content Writer & 64.67 & 56.43 & 61.29 & 52.43 & 57.93 \\
\hline Hardware Engineer & 61.56 & 55.67 & 59.76 & 57.36 & 45.73 \\
\hline
\end{tabular}

\section{V.IMPLEMENTATION}

The proposed system is implemented in real world to investigate its validation. The purpose of the investigation is to check the precision of personality mining and recommendation of job. The experimentation is conducted on the students who have just completed their engineering degree in computer science or information technology and are looking for the job. Here we are showing how the suitable job can be recommended to any job seeker.

Step wise implementation for one candidate is as follows:

1. Data Collection: Firstly, the candidate is asked to fill the MBTI based questionnaire in the specified time. Time limit is enforced so that the candidate cannot bluff. Moreover, each question is compulsory. Questions are picked randomly from the database from each category. After that he is asked to fill the education qualification details along with most scoring subject and the subject of his interest. The candidate's desired job profiles is also asked.

2. Experimental Result: Depending upon the response of the candidate, score is obtained for each of the eight attributes of MBTI. The value of the score varies between 4 and 20 . The table 3 shows the MBTI score obtained by the candidate.

TABLE III

MBTI SCORE OF A CANDIDATE

\begin{tabular}{|l|l|l|l|}
\hline Extrovert & 13 & Introvert & 11 \\
\hline Sensing & 14 & Intuitive & 13 \\
\hline Thinking & 13 & Feeling & 11 \\
\hline Judging & 15 & Perceiving & 12 \\
\hline
\end{tabular}

3. Then, the obtained MBTI score is mapped over OCEAN theory using the table 1 . This is done because dimensions proposed by OCEAN theory are closer to the personality traits required suggesting jobs than MBTI. The result after mapping is shown in figure 3 as a screen shot.

4. Moreover, score for educational qualification is obtained while considering education qualification, most scoring subject, subject of his interest and his desired job. All desired jobs are weighted 40. If most scored subject is same as subject of his interest, weight 50 is given otherwise they are given weight of 45 each. 


\section{OCEAN Analysis :-}

\section{Bar Chart}

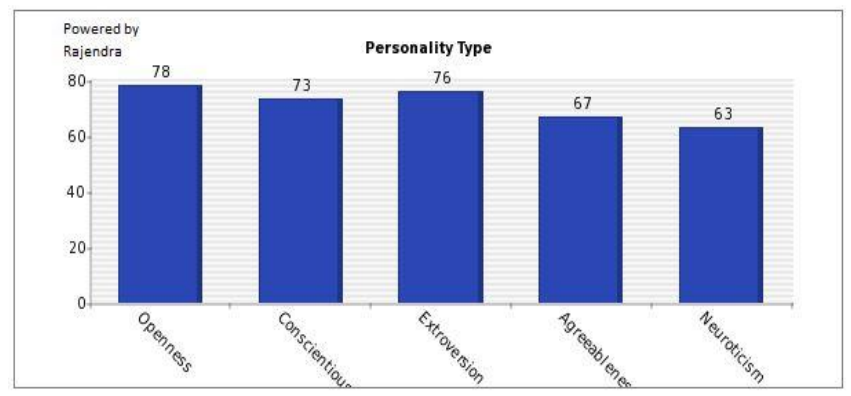

Fig 3. Result of MBTI to OCEAN Mapping for a candidate.

5. Finally, scores from personality mining and educational mining are coalesced together (as explained earlier) to find compatibility index of different jobs as per the recommendation of our model. Final output is shown in figure 4.

$\begin{array}{ll}\text { JOB CATEGORY } & \text { COMPATIBILITY INDEX } \\ \text { WEB DEVELOPER } & 78 \% \\ \text { SOFTWARE DEVELOPER } & 75 \% \\ \text { R \& D } & 67 \% \\ \text { DATA ANALYST } & 64 \% \\ \text { CONTENT WRITER } & 62 \% \\ \text { HARDWARE ENGINEER } & 66 \%\end{array}$

Fig 4. Screen shot of priority wise job recommendation for a candidate having engineering degree.

To validate the model, we collected a corpus data of 100 job seekers and estimated their personality and educational qualification in the same manner as explained above. Then, a list of six ideal jobs prioritize on the basis of compatibility index was suggested to all 100 applicants. Thereafter, they were asked for the feedback that how they feel about the suggested job. Is it actually the most suited one? In the feedback collection it was found that $51 \%$ applicants agreed with first job in the priority list, $22 \%$ applicant agreed with second job, $18 \%$ agreed with one of job between third to sixth option and remaining $9 \%$ disagreed with the recommendation.

\section{CONCLUSION AND FutURE SCOPE}

In the paper, E-PE Job (a Job Advisory System) based upon personality and education mining is proposed. The system implements automated ranking of jobs based on a set of criteria which can help the job seeker to search for a most appropriate job. The objective is to recommend the ideal jobs to a job seeker while conducting personality mining and education mining both. The model is successfully validated in the real world scenario. We have conducted the experimentation on 100 students who have earned an engineering degree in the field of computer science, information technology. However, the same architecture can easily be extended to other educational degrees also.

Next, we are working to build the same on a larger platform with much larger database. Moreover, we are working for extracting the personality factors more accurately by getting the data from some social networking sites.

\section{REFERENCES}

[1] B. I. Myers, M. H. McCaulley, "A Guide to the Development and Use of the Myers-Briggs Type Indicator" (2nd ed.), Consulting Psychologists Press, 1995.

[2] E. Faliagka and A. Tsakalidis, "An integrated e-recruitment system for automated personality mining and applicant ranking", Internet Research, vol. 12(5), 2012, pp 551- 568.

[3] E. Faliagka, L. Kozanidis, S. Stamou, A. K.Tsakalidis, G.Tzimas, "A Personality Mining System for Automated Applicant Ranking in Online Recruitment Systems" ICWE 2011, pp 379-382.

[4] F. Tian, S. Wang, C. Zheng, Q. Z. Abbrev, "Research on E-learner Personality Grouping Based on Fuzzy Clustering Analysis", CSCWD, 2008, pp 1035-1040.

[5] G. M. Luis, J. R. Castro, G. Licea, A. R. Diaz, and R. Salas, "Implementing Fuzzy Subtractive Clustering to Build a Personality Fuzzy Model Based on Big Five Patterns for Engineers", MICAI 2013, Part II, LNAI 8266, 2013, pp. 497-508.

[6] J. W. Lounsbury, R. P. Steel, L. W. Gibson, A. W. Drost, "Personality traits and career satisfaction of human resource professionals", Human Resource Development International, vol. 11(4), 2008, pp 351-366.

[7] K. Cave, "Leadership challenges for MBTI confirmed introverts", Available http://www.idgconnect.com/blog-abstract/7917/leadershipchallenges-mbti-confirmed-introverts, 2014.

[8] P. Meo, g. Quattrone, G. Terracina and D. Ursino, "An XML-Based Multi-agent System for Supporting Online Recruitment Services"., IEEE Transactions on Systems, Man, and Cybernetics, vol. 37(4), 2007, pp.464-480.

[9] P. T. Costa Jr. and R. R. McCrae, "Revised NEO Personality Inventory (NEO-PI-R) and NEO Five-Factor Inventory (NEO-FFI) professional manual", Odessa, FL: Psychological Assessment Resources, 1992.

[10] Q. Yang, J. Wang, "Research on Learners' Personality Mining Based on Improved Decision Tree Algorithm", In Proc of Second International Conference on Genetic and Evolutionary Computing, 2008.

[11] R. R. McCrae, P. T. Costa Jr, "Reinterpreting the Myers-Briggs Type Indicator from the perspective of the five-factor model of personality", Journal of Personality, vol. 57, 2008, pp 17-40.

[12] V. L . Nagarjuna, S. Mamidenna, "Personality Characteristics of Commerce and Engineering Graduates - A Comparative Study", Journal of the Indian Academy of Applied Psychology, vol. 34(2), 2008, pp 303-308.

Rajendra S. Choudhary was a graduate student at Jaypee Institute of Information Technology, Noida, India. His area of interest is e- learning and recommendation systems

Rajul Kukreja is a graduate student at Jaypee Institute of Information Technology, Noida, India. His area of interest is artificial intelligence and data mining.

Nitika Jain is a graduate student at Jaypee Institute of Information Technology, Noida, India. Her area of interest coginitive science, personality mining, e- learning.

Shikha Jain is assistant professor in Jaypee Institute of Information Technology, Noida, India. Her research area are affective computing, intelligent agents, information retrieval. 